\title{
A Discussion on Competency Management Systems from a Design Theory Perspective
}

Competency development is a critical success factor for organizations and their employees when it comes to competitiveness. Competency Management Systems contribute to systematic competency development within organizations by supporting processes such as needs identification, intervention planning and implementation, and evaluation. However, designing Competency Management Systems comes with a broad range of technical and organizational challenges. This study presents systematically elaborated design recommendations for Competency Management Systems in order to overcome these challenges. The design recommendations in the categories organization, user, resources, and competency management software range from attention management to activating stakeholders by organizational structures and values.

DOI 10.1007/s12599-010-0134-4

\section{The Author}

\section{Dr. Bernd Simon ( $\varangle)$}

Institute for Information Systems and New Media

Vienna University of Economics and

Business

1090 Vienna

Austria

bernd.simon@wu.ac.at

Received: 2009-07-30

Accepted: 2010-09-03

Accepted after six revisions by

Prof. Dr. Buhl.

Published online: 2010-11-09

This article is also available in German in print and via http://www. wirtschaftsinformatik.de: Simon B (2010) Gestaltungstheoretische Überlegungen zu Kompetenzmanagementsystemen. WIRTSCHAFTSINFORMATIK. doi: 10.1007/s11576-0100251-1.

(C) Gabler Verlag 2010

\section{Introduction}

\subsection{Practical Relevance of Competency} Management in Organizations

The competencies of its employees are a critical success factor for any organization (Devaraj and Babu 2004, p. 63).
Especially when it comes to change, for example as a result of an economic slowdown or the introduction of management innovations and new products, competency development plays a significant role (Deiser 2009, pp. 45-50; Simon et al. 2008, p. 96; Hamel 2007, p. 41). At the same time, an increased individual demand for developing competencies in order to meet increased employability requirements, such as dealing with complexity, dynamics, interconnectedness, and insecurity, can be derived (Erpenbeck and Sauter 2007, p. 7). In consequence, organizations are increasingly required to get involved in the development of their employees' competencies (Heyse and Ortmann 2008, pp. 1922; Zwick 2004, p. 663).

Controlling competency development is considered competency management; it is a management function that is also referred to as human resource (HR) development. In practice, HR development comprises all actions that serve the systematic development of employee competencies (Solga et al. 2008, p. 19). HR development has been changing in recent years: Aspects such as cost reduction, alignment with the overall performance goals of the organization, and targeted talent management have increasingly become the focus of attention, while the strategic relevance of HR development is increasingly acknowledged by managers (Faltin and Zimmermann 2009, pp. 6-7; Heyse and Ortmann 2008, pp. 20-21).

In such an environment, information systems play a major role. Informa- tion systems are considered to be systems that collect, process, store, and distribute information to support decisionmaking processes (Laudon and Laudon 2005 , p. 8). From the perspective of organizational theory, information systems are socio-technical systems that comprise not only information and communication technology (hardware and software), but also human components (users with certain competencies) and the organizational environment of the system (structures and processes) (Picot and Baumann 2009 , p. 72). This paper deals with information systems that support competency management, termed Competency Management Systems (CMS) in the following.

Available software products for developing CMS have advanced considerably in recent years. Competency management software now provides substantial functionalities for identifying competency development needs and for designing and evaluating competency development processes (Erpenbeck and Sauter 2007, pp. 273-276). Talent management software is a more recent development within competency management software and adds functions to identify critical roles and tasks and to supply crucial competency development actions for certain target groups, so-called talents (Heyse and Ortmann 2008, p. 11).

Introducing competency management software and the related development of a CMS confronts companies with particular challenges, for example: 
- How can we make sure that all individuals relevant for competency development, such as managers, learners, or HR developers, are sufficiently involved and supported in their decision-making process?

- How can we design CMS to facilitate the involvement of crucial external resources, such as lecturers or learning materials, in all relevant processes?

- How can we intensify and improve competency management?

- How can we facilitate access to software, methods, and contents particularly for small and medium-sized enterprises that do not have well-defined structures for supporting competency development?

This study deals with those and related questions and for this purpose discusses CMS design recommendations.

\subsection{Research Rationale and Scientific Relevance}

Human resource management is generally considered a pioneering area when it comes to Business and Information Systems Engineering (BISE), in particular the use of enterprise resource planning software (Strohmeier 2000, p. 90). However, this does not apply to the area of competency management, which has changed significantly in recent years. Although the relevance of competency management has increased in the last decade both in business practice and in organizational theory, it has been neglected by BISE and related disciplines to a great extent (Hasenkamp and Stahlknecht 2009, p. 6; Lindgren et al. 2004, p. 436; Strohmeier 2000, p. 90).

Within the discipline of Information Systems, international research in recent decades mainly developed behavioral models for measuring technology acceptance (Venkatesh 2000) or the success of information systems from an organizational point-of-view (DeLone and McLean 2003). These models mainly serve to explain the success of information systems in retrospect and list a few factors such as the perceived usefulness with regard to one's own performance or the perceived ease of use (Davis 1989, p. 320). Design recommendations for information systems that also consider the characteristics of CMS can only be derived from these models to a very limited extent. Their focus is more on the development of generally applicable explanatory models.
From the perspective of organizational theory, those works are part of the resource-based view of the firm, which is mainly used to explain existing, real economic phenomena (explanatory function). The design function of the theory, however, has hardly been researched yet. "[Thus,] in the future, resource-oriented research should focus not only on listing business resources, potentials and core competencies, but also on showing how such values can be created and protected (Macharzina and Wolf 2008, p. 69)". This study starts off at this point by developing design recommendations for CMS, thereby showing how such information systems can be designed effectively in order to increase individual competencies to a degree that is relevant for the organization as a whole and in consequence improves its competitiveness.

This study ties in with the research mentioned above and elaborates on the development of CMS from a design science perspective. Following the paradigm of design science, fundamental business theories (so-called kernel theories) were used to derive the basic requirements of CMS and to convert these into a prototype. Inspired by action research, the prototype was then compared with the "real world" requirements of organizations elicited by qualitative interviews. Success factors for the design of a CMS were derived from the interviews using content analysis.

This paper is structured as follows: Sect. 2 describes the method of the research project. Section 3 discusses the relevant theoretical foundations of HR development in organizations. Section 4 focuses on the core concept of this study, the competency management system and, supported by theory, defines the requirements. Section 5 presents the prototype and the results of the evaluation as well as limitations of the study. All results of the research are summarized again in Sect. 6 and discussed from a scientific viewpoint.

\section{Epistemological Positioning and Research Method}

\subsection{Epistemological Positioning}

This study can be assigned to the design science research paradigm. Applied to Information Systems, this research paradigm suggests to develop and evaluate artifacts in order to resolve previously defined problems of the interaction of technology and social systems (Gregor and Jones 2007, p. 314; Hevner et al. 2004, p. 77).

Gregor and Jones (2007, p. 321) distinguish between artifacts relevant for information technology, such as prototypes, and those relevant for information systems, such as design principles, where prototypes may contribute to the development of the latter (Hevner et al. 2004, p. 77). This is also the role of the prototype in this study.

The objective of this research project is to come up with a range of relevant design principles for developing CMS. Design principles for information systems comprise, for example, user requirements and system functions as well as principles for effective development or effective operation (Markus et al. 2002, p. 181).

In this context, scientific progress becomes manifest in the testable propositions that have been developed in this study by means of an expository instantiation followed by a qualitative evaluation with subsequent content analysis of the interview transcriptions.

\subsection{Research Method}

In order to develop testable propositions for a successful design of CMS, the focus of this study was on the evaluation phase, which is based on the principles of action research (Davison et al. 2004, p. 69):

1. the principle of the researcher-client agreement on the action research project,

2. the principle of the cyclical process model,

3. the principle of theory,

4. the principle of change through action, and

5. the principle of learning through reflection.

Action research is a social sciences research approach that, thanks to its practical orientation, is well suited for information systems and design sciences research (Baskerville and Wood-Harper 1998, p. 90). The distinctive feature of action research is its interventionary approach that addresses a relevant problem from a scientific and a practical perspective (Easterby-Smith et al. 2008, p. 165) and records the problem within the researcher-client agreement.

The prototype developed for this project is an alternative to in-house standard software especially for mediumsized companies, where two areas of application are distinguished: "In-house competency development" focuses on 
HR development that is mainly controlled in-house, which is why the contact partners involved were representatives of HR departments and managers. The second area of application targets consulting companies, who can use the portal as a solution for implementing competency development projects for their clients. In consequence, the prototype was presented to training providers. Primary users in this scenario are external consultants and trainers who conduct analyses, interventions, or evaluations as requested by their clients.

In total, there has been contact with 55 enterprises over two years as part of the research project. Of those 55 companies, 15 agreed to evaluate the prototype. Changed economic conditions but also different degrees of interest in the problem at hand led to different levels of commitment and - in the sense of action research - to interventions of varying intensities. Six of the fifteen companies introduced the system and were in consequence subject to a "deep" intervention. A further nine went through a pilot operation and a demonstration phase with selected users.

The introduction or demonstration was accompanied by interviews that served as a means of joint reflection of researchers and industry practitioners. Depending on the degree of involvement of the company, one to three interviews with different officials were conducted. Table 1 gives an overview of the involved functions and the respective number of interviews.

The interviews were semi-structured and followed an interview guideline that, in accordance with the qualitative approach applied, changed over the course of the project (Rubin and Rubin 1995, pp. 43-48). During the interviews, information about the companies and the contact persons, any implemented CMS, an assessment of the current state, the success factors of further development as well as feedback with regard to the prototype was gathered.

In this context, companies were selected based on the maximum achievable level of heterogeneity (Patton 2002, p. 234). As a consequence of this strategy, employees of both big corporations (especially regarding application area (1)) and small consulting companies with less than 50 employees (here especially application area (2)) were surveyed.

Table 1 Evaluation: Officials involved and number of interviews

\begin{tabular}{|c|c|c|c|c|c|c|}
\hline Company & $\begin{array}{l}\mathrm{HR} \\
\text { manager }\end{array}$ & $\begin{array}{l}\text { Internal } \\
\text { knowledge } \\
\text { manager }\end{array}$ & Manager & $\begin{array}{l}\text { External } \\
\text { training } \\
\text { provider }\end{array}$ & $\begin{array}{l}\text { Internal } \\
\text { training } \\
\text { provider }\end{array}$ & $\begin{array}{l}\text { Software } \\
\text { introduced? }\end{array}$ \\
\hline A & 3 & & & & & Yes \\
\hline B & 3 & & & & & Yes \\
\hline C & 2 & & & & & Yes \\
\hline $\mathrm{D}$ & & & & 2 & & Yes \\
\hline $\mathrm{E}$ & & & & 3 & & Yes \\
\hline $\mathrm{F}$ & & & 1 & & & Yes \\
\hline G & & & 1 & & & No \\
\hline $\mathrm{H}$ & & & 1 & & & No \\
\hline I & & & 1 & & & No \\
\hline $\mathrm{J}$ & & & & & 1 & No \\
\hline K & 1 & 1 & & & & No \\
\hline $\mathrm{L}$ & 1 & & & & & No \\
\hline M & 1 & & & & & No \\
\hline $\mathrm{N}$ & 1 & & & & & No \\
\hline $\mathrm{O}$ & 1 & & & & & No \\
\hline
\end{tabular}

The interviews were transcribed and analyzed subsequently. The objective of the qualitative content analysis was the identification of themes, patterns, and categories that were relevant for the researched phenomenon (Easterby-Smith et al. 2008, p. 175). The summarizing content analysis used here was implemented in a three-step process (Mayring 2010, pp. 59-62):

1. summarized paraphrasing of the interviews,

2. generalization of the paraphrases,

3. reduction by means of selection, bundling, construction, and integration of paraphrases.

At the end of each reduction phase, it was meticulously assessed whether the new statements, which were summarized in a category system, did indeed represent the entire raw information. In addition, the reductions to some extent used quantitative perspectives of the data in order to gain more information with regard to the relevance of the respective design recommendation. The Appendix elaborates on this process by using the design recommendation "Benchmark Values" as an example.

The objective of this procedure was an analytical generalization in order to develop propositions that have a more general relevance (Mayring 2010, p. 320). The generated propositions are to be considered theory-developing (vs. theory-validating) (Atteslander 2008, p. 200).

\section{Theoretical Foundations of Human Resource Development}

\subsection{Competencies of Organizations and Their Members}

The resource-based view of the firm assumes that success or failure of companies is predominantly determined by their core competencies (Macharzina and Wolf 2008, p. 65). Core competencies are abilities developed through learning processes that coordinate the resources used in the company (Prahalad and Hamel 1990, p. 82). These abilities are "embedded" in the competencies of the members of the organization and in the organization's processes and structures (Argote et al. 2003, p. 579).

The discipline of organizational psychology which is relevant in the context of HR development gives the term competency yet another meaning, since from an organizational psychology perspective competencies describe the personal abilities of an individual (dispositions) as regards self-management (Erpenbeck and Sauter 2007, p. 65). In consequence, qualification, in terms of an individual's ability to act, is supplemented by aspects such as rules, norms, values, and attitudes, but self-management is the focus at the same time (Erpenbeck and Sauter 2007, p. 69). The development of rules, norms, and values within an organization is a crucial prerequisite in this context (Heyse and Ortmann 2008, p. 14). 
Thus, the development of core competencies requires organizations to develop qualifications on employee level, whereas the organizational psychology perspective also requires the development of rules, norms, and values for this purpose. Training employees is supplemented by "learning values" (Erpenbeck and Sauter 2007, pp. 68, 69). The HR development derived from the business needs and supplemented by learning values in this sense also includes aspects of organizational learning (Argote et al. 2003, p. 579). CMS play a special role in this context as they mirror processes that control such competency development. Thus, they support companies in developing competencies that are rooted deep within the organization and cannot (or only under extreme effort) be sourced externally (Czerny 2009, p. 23; Macharzina and Wolf 2008, p. 67).

\subsection{Particular Characteristics of Competency Development Interventions}

The provision of competency development interventions is a set of services with very specific characteristics. Often, external knowledge sources have to be involved for these services to be delivered. This, however, is a particular challenge for process management and information system design.

From an economic viewpoint, services as well as the provision of competency development interventions can be classified according to the degree of involvement of external resources (Engelhart et al. 1993, p. 401). In order to make sure that competency development is aligned with the organizational requirements, competency development interventions require close interaction of different internal and external stakeholders, including managers, employees, HR managers, external lecturers, and external training providers (Faltin and Zimmermann 2009, p. 6).

Optimizing the information and communication processes surrounding the involvement of external resources has the potential to significantly affect the provision of services (Simon et al. 2008, p. 96; Hertel and Konradt 2004, pp. 10-14). An information flow between the service provider and the client improved by a CMS creates opportunities for individualizing the service - a significant success factor for competency development interventions (Simon and Treiblmaier 2007, p. 344 ) - and reduces the procurement risk.

\section{Basic Requirements of Competency Management Systems}

In the context of this study, competency management systems are information systems used for competency development. Based on the definition of information systems in Sect. 1 as well as the theoretical foundations of HR development, competency management systems within this paper are defined as follows: competency management systems are socio-technical systems that use competency management software to enable users to develop their competencies within the context of their organization and in this context provide decision support when it comes to the involvement of external and internal resources.

Implementing this sort of competency management requires the collection of all information relevant for competency development (such as performance indicators, training needs, evaluation data of lecturers) and the response to this information (such as the design of an individual development plan, the provision of training opportunities, the support of lecturers)

Competency development processes can be structured according to a threephase model (Erpenbeck and Sauter 2007, pp. 273-276), similar to what knowledge management contributions (Probst et al. 2000, p. 30), training evaluation research (Seeber 2000, p. 37), and HR development literature (Sonntag 2005, p. 25) suggest:

(1) Analysis: Needs and goal analysis for systematically isolating competency development needs and goals.

(2) Intervention: Designing and realizing competency development measures using adequately prepared learning and transfer environments.

(3) Evaluation: Assessing the competency development success.

In order to collect the management information relevant to competency development, the different phases use different methods that will be briefly discussed in the subsequent paragraphs.

\subsection{Analysis of Competency Development Needs}

The methods of the analysis phase can be differentiated according to whether they are based on an analysis of the organizational goals or are derived from the organizational strategy, whether they are fo- cused on an analysis of tasks and requirements or whether they focus on individual needs (Heyse and Ortmann 2008, p. 14; Rosenstiel 2006, p. 109).

The career development discussion, also referred to as performance review, performance or employee appraisal, deals with the individual members of the organization and their performance, but with matching resources, the method can also be used for measuring competency alignment with the organizational strategy. In recent years, this method has become an important activity for determining the individual competency development needs. The three main functions of the employee appraisal are the provision of feedback for the employee, the identification of development needs as well as the agreement on goals (Schuler and Görlich 2006, p. 254).

In 360-degree feedbacks, managers' competencies relevant for the organization are recorded and assessed. The multi-perspective data collection initially comprised a self-assessment as well as an assessment by employees, peers, and superiors and was later extended to external stakeholders such as trainers, consultants, and clients (Edwards and Ewen 2000 , p. 42). For this reason, 360-degree feedback is also called multi-rater assessment. In 360-degree feedback, the questionnaire is particularly important because it must consider company-specific competency requirements while fulfilling the criteria of validity and reliability.

The learning needs analysis is task- and demand-oriented and supports HR developers in planning training opportunities such as courses. The analysis is typically implemented by means of a survey targeted at managers before the elaboration of the in-house training program. The procedure is the same for employee surveys with an HR development focus; however, such surveys go beyond competency development needs and also analyze the organization as a learning and transfer environment (Simon and Treiblmaier 2007, p. 335).

\subsection{Intervention}

Intervention, which is when actual competency development occurs, can take on different forms (see Sect. 3.2) that differ in their materiality and degree of individualization. Formal, non-formal, and informal learning formats (EC 2001, 
p. 17) contribute to competency development within an organization. A formal learning format, such as an Executive MBA program, is any kind of qualification provided by education providers that completes with a certificate. Nonformal learning formats are structured like formal learning formats; for example, learning objectives are defined and a curriculum is adhered to. However, no formally recognized degrees are involved in such learning formats. Informal learning is based on day-to-day experiences and subject to an unstructured learning process; however, informal learning can also be organized with structures and processes supported by information and communication technology (ICT), whereas here - as with knowledge management - a personalization strategy is distinguished from a codification strategy (Maier and Hädrich 2001, p. 498). Depending on the degree of formalization, management of competency development is either centered on the education provider or at the target organization. Ideally, a CMS must consider competency development interventions of all formats.

\subsection{Evaluation of Competency Development}

When it comes to the evaluation of the intervention, it is usually differentiated between formative (informing) and summative (measuring) evaluations (Caffarella 2002, p. 225). Formative evaluation has the objective to positively influence the intervention. Reflection instruments that are used before or during the knowledge transfer attempt to align stakeholders' expectations and the design of the intervention. This approach is similar to learning contracts; however, those have a higher degree of formalization. A learning contract is an agreement between a learning individual and its manager. It involves the definition of learning goals and learning strategies as well as opportunities for assessing the learning outcomes (Knowles 1986, p. 38). Similar to the formative evaluation, a learning contract is designed to have a direct controlling effect on the learning environment.

Documenting competency development success and the resulting improvements in business performance are essential aspects of competency management (Heyse and Ortmann 2008, p. 14). Kirkpatrick's four-phase model has gained considerable popularity when it comes to the summative evaluation of structured learning formats; it differentiates between measuring satisfaction (reaction), learning outcomes (learning), change in behavior (transfer), and the business impact of learning in the transfer environment (result) (Kirkpatrick and Kirkpatrick 2005, pp. 21-26). Measuring the business impact of learning has been further advanced in recent years under the heading "Return-on-TrainingInvestment” (Phillips 2003, p. 35).

\section{Prototype Development and Evaluation}

\subsection{Prototype Development}

To discover corresponding design opportunities of the competency management software, a prototype was developed. Table 2 lists the competency management services derived from the basic requirements (see Sect. 4). They are based on the methods described above and go back to basic services. They support HR developers, managers and external consultants as well as trainers in their task of analyzing the competency needs within an organization (for example with 360-degree feedback), implementing interventions (for example with learning management), and evaluating their success (for example with learning transfer analysis).

The prototype provides competency management services as a portfolio of software services that can be flexibly configured to any company needs. The software-as-a-service solution does not

Table 2 Implemented services of the prototype

\begin{tabular}{|c|c|c|}
\hline Basic requirements & $\begin{array}{l}\text { Competency management } \\
\text { services }\end{array}$ & Basic services \\
\hline Needs and goal analysis & $\begin{array}{l}\text { 360-degree feedback, } \\
\text { employee appraisal }\end{array}$ & \multirow{7}{*}{$\begin{array}{l}\text { User administration, file storage, } \\
\text { calendar, forum, photo album, } \\
\text { mail templates, sample questions, } \\
\text { performance indicators, } \\
\text { competency catalog, contact } \\
\text { management, Wiki }\end{array}$} \\
\hline Intervention & Learning management & \\
\hline \multirow[t]{5}{*}{ Evaluation } & $\begin{array}{l}\text { Learning outcome } \\
\text { assessment, learning } \\
\text { transfer analysis, course } \\
\text { evaluation }\end{array}$ & \\
\hline & Evaluation & \\
\hline & Learning transfer & \\
\hline & measuring & \\
\hline & Event evaluation & \\
\hline
\end{tabular}

require on-site installation at the client's site and provides a portfolio of reusable content for all registered companies. This includes questionnaires for course evaluations and employee surveys with an HR development, lists of figures for performance and activity reports of human resource departments (so-called HR controlling) as well as competency catalogs. Figure 1 shows a screenshot of a competency catalog that is used in 360-degree feedback, for example. In the meantime, the prototype has successfully been marketed and is being used by 15 organizations as of August 2010.

\subsection{Evaluation Results} interviews lead to results that can be allocated to the four components of CMS (see Sect. 4).

\subsubsection{Structures and Processes of the Organization}

Common definition of goal: Before a CMS is introduced, the stakeholders involved in the competency development processes must be identified and should have the opportunity to influence the definition of the goal and the implementation of the processes. Many interview partners confirmed that such a procedure is desirable and that social aspects with regard to the project definition determine the success or failure of a CMS already at a very early stage.

Controlling attention: Competency management comprises a set of processes that happen simultaneously to the core business processes of a company. Some of the parties interviewed in this
The results of the content analysis of the 
Fig. 1 Screenshot of competency catalog at 2 know2.com

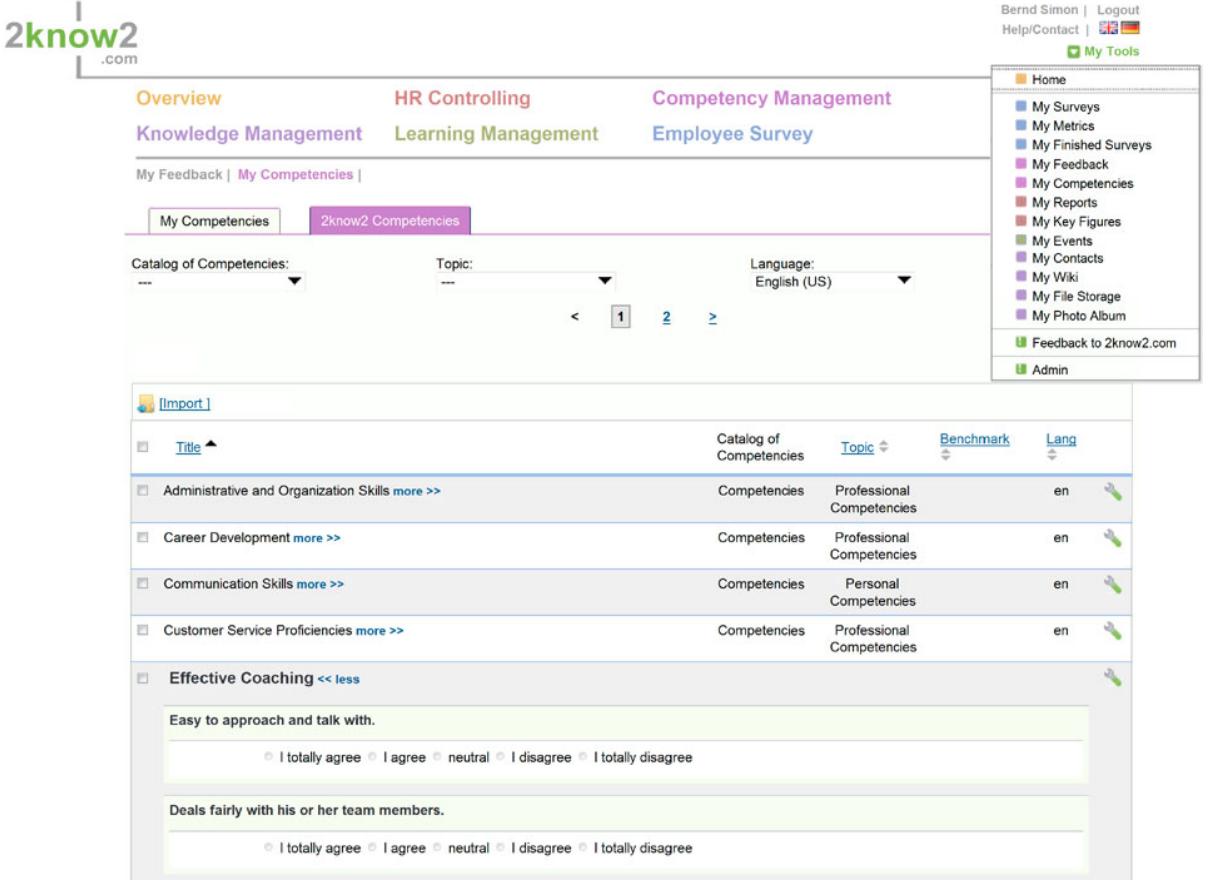

context would like to integrate functionality in the CMS to direct the attention of the involved parties towards competency management. CMS that place emphasis on controlling attention for this reason seem particularly promising.

Involving reflection on data: Many participants identified the level of intensive reflection on the data collected with competency management software, which involved all relevant stakeholders, as a key activity for the successful operation of a CMS. Misleadingly, the automatisms mirrored by a CMS sometimes suggest a complete analysis of a phenomenon relevant for competency development. However, in some cases, only a comprehensive discussion involving all stakeholders can lead to a positive change.

Besides the processes, other success factors relevant for competency development and linked to the organization can be identified.

Compatibility with established communication culture: Companies establish different types of communication cultures, especially regarding the use of electronic media. On few occasions, participants commented that the introduced competency management software had to be compatible with this culture or that action to change the culture had to be taken if required.

Learning culture: The introduction of a CMS comes with certain demands on the organizations, which, apart from process-related changes, require certain attitudes towards learning. Across companies and application areas, it became clear that the success of a CMS is closely concatenated with the existing learning culture within the company. CMS can be successfully established in an organization if training and learning at the workplace are considered important and if a company is perceived as an organization that is ready to invest in learning and change. On an organizational level, the "motivational" prerequisites must be provided (for example striving for excellence, customer orientation, avoidance of errors). At the same time, there must be enough freedom for personal and organizational development.

Sufficient provision of resources: Another aspect that was emphasized across companies and application areas was that sufficient resources are critical for the success of a CMS project. A particular challenge is the allocation of internal human resources to control the CMS project. A presentation of improvements in efficiency and effectiveness on a medium term basis can help to create the required resource allocation. In this context, expert knowledge of the CMS project plays a key role because it contributes to the realization of improvements in efficiency and effectiveness.

\subsubsection{Users and Their Competencies}

Methodological competency: CMSsupported activities such as employee appraisal, 360-degree feedback, or employee surveys require specific competencies of methods. The key employees of the respective processes (for example managers, HR developers) must have the required knowledge in order to ensure a successful implementation - something that external training providers emphasized in particular. Learning modules integrated in the CMS could help in this regard.

Degree of activation of stakeholders: The manager has a key role in both the implementation of a learning-oriented corporate culture and the operative support during the introduction and operation of CMS. Moreover, managers are important in the operative control of learning because they have to significantly contribute to areas ranging from the definition of learning objectives relevant for the organization and the selection of the interventions to the evaluation - especially internal training managers and HR managers mentioned this. Conversely, managers said that the aforementioned members of the organization should also get involved in the core business and in this way get an understanding of the main challenges. Similarly, external training providers (such as trainers or workshop organizers) must be involved in the processes and informed about learning objectives and learning evaluation. However, it is also the learners themselves who have a crucial role in the implementation. Attitudes such as 
readiness to change or striving for organizational improvements in day-to-day work significantly contribute to the successful implementation of CMS.

\subsubsection{Available Input and Control Resources}

Input resources: A CMS benefits tremendously from input resources, such as courses, trainers, or electronic learning content. Both the participants' satisfaction with these services and the successful implementation in business practice seem to be essential for the success of CMS, irrespective of the company and the application areas.

Such performance measurement again makes use of control tools, such as templates, benchmark values, and expert knowledge, all of which support competency management by collecting and presenting information.

Flexible templates: The provision of templates for performance indicators, survey instruments, and competency catalogs speeds up the introduction and operation of CMS. A qualitatively top grade and comprehensive as well as well-structured template catalog seems to be very helpful for a quick project launch, especially for medium-sized organizations and from the viewpoint of the HR manager. Templates then have to be amended so that they are selfexplanatory. Support of the selection process with tutorials or consulting is desirable.

Some participants said that the benefit of templates is significantly reduced if they cannot be sufficiently adapted. The strategy and culture of the organization as well as the internal use of language define requirements for adapting the used performance indicators, instruments, and templates that must be considered.

Benchmark values: Benchmark values for the provided instruments, performance indicators, and competency models are an additional benefit for some companies. Internal benchmarks for evaluating training providers are of particular interest. Using external benchmark values within the company, however, requires transparency in calculating them because the data of the benchmark partners must match the in-house data.

Company-wide expert knowledge: The demand for adequate methodical competencies of the users led, in some cases, to the recommendation that the CMS should offer options to teach users the required methodical competencies. This can be done using pre-defined learning contents (codification strategy) or using experts who are familiar with such themes (personalization strategy).

\subsubsection{Competency Management Software}

Usability: The better the usability of competency management software, the more likely it should be possible to involve stakeholders that do not consider competency management as one of their core activities. The interviews frequently confirmed common requests for usability such as a clear, well-structured user interface, transparent navigation structures, or attractive visual design.

Adaptable functionality: Despite a high degree of perceived "standardization" of the various competency management methods, the adaptability of the functionality is a core software trait for many participants. Surveys, for example, can be anonymous or not, or they may use anonymous codes. Course registration may require the integration of participation conditions or approval by one or several managers. The definition of feedback processes can be done by the HR manager, external consultants, or the feedback recipients themselves. Thus, competency management software must be sufficiently flexible, as some of the participants said.

Interoperability: The operation of competency management software requires a range of interfaces with other internal and external information systems. These interfaces avoid redundancies in employee data and therewith increase efficiency. Interfaces are also very important for processing the collected information and for the collaboration surrounding them and thus contribute to a more effective CMS. Although no IT specialists were asked, the requirement "interoperability" was mentioned quite frequently.

Transparency of competency development processes and results: In a few rare cases, the new transparency created by CMS was mentioned as an additional asset. Since the data available in the competency management software can be mined flexibly and comprehensively, they are a key aspect for an improved control over competency development. For this reason it is important that - considering employment legislation - stake- holders have access to the respective control information. The ease of collecting and accessing information relevant for competency development, such as existing competencies or competency development goals, the perceived learning transfer, event quality, or the implementation of HR leadership, create new opportunities for increasing the effectiveness of the organization. Meta control information, such as the number of filled out questionnaires or conducted employee appraisals, create additional transparency in respect to the implementation of the processes relevant for the CMS.

Privacy protection: Personal data available in competency management software, such as employee information, competency profiles, or completed trainings, are generally considered very personal and confidential data. This means that users are very interested in being able to control the visibility of such data. Some HR managers said that transparency as regards training services could cause disapproval even if it is just across departments. At the same time, confidentiality of the collected data, especially in surveys, must be ensured and, for example, options to answer anonymously should be created. Many participants said that dialogs for user prompting must ensure that the competency management software is considered a trustworthy medium that protects one's privacy.

\section{Summary and Research Implications}

This study presents design principles for CMS by first delineating relevant key terms, fundamental theories, and basic requirements. Based on a prototypedriven evaluation with a subsequent content analysis of interview transcriptions, a range of design recommendations (socalled propositions) could be identified in order to support a person-centered development of core competencies. The developed propositions are to be considered theory-developing (vs. theoryvalidating) (Atteslander 2008, p. 200). In order to check the general validity of the propositions, the integration of the recommendations in a model would have to be implemented and tested. Quantitative research based on such an effectiveness model would yield additional insight 


\section{Abstract}

Bernd Simon

\section{A Discussion on Competency Management Systems from a Design Theory Perspective}

The competencies of employees are a critical success factor for any organization. Competency Management Systems help to develop competencies by supporting processes such as needs identification, intervention planning and implementation, and evaluation. However, the design of Competency Management Systems comes with a broad range of technical and organizational challenges. This study addresses these challenges and discusses the development of Competency Management Systems from a design theory perspective. The prototype evaluation, conducted as part of an action research initiative, involved fifteen companies and identified design recommendations in the areas of organization, user, resources, and competency management software.

Keywords: Competency Management Systems, Resource-based view of the firm, Human resource development, Learning management, Design sciences, Prototype evaluation, Action research into the different meanings of the individual design recommendations. Before this happens, however, the identified design principles need to be further elaborated and differences between different application areas and types of users need to be analyzed.

A focus on talent management with the new functions of recruitment, talent identification, performance review, and succession planning (Steinweg 2009, p. 8) would be a valuable sequel to this research project.

A noteworthy limitation of the current state of research is that a competencyoriented control of learning activities, which is also the basis of this study, is only one of many ICT-supported, personfocused practices that affect a company's performance. Management literature also refers to control-, commitment-, and remuneration-oriented management theories (Sonntag 2005) that still need to be researched as a theoretical basis of CMS.

This study was mainly implemented in the context of competency development interventions based on formal control methods as well as on formal and non-formal learning formats. Extending it to informal learning formats may yield new additional results and further close the gap between knowledge management and competency management.

\section{Acknowledgements}

This study was supported by the 6th framework program of the European Commission (Research project "PROLIX - Process-oriented Learning and Information eXchange", Contract No. 027905). Furthermore, the author would like to thank all involved staff members and students at the chair for "Wirtschaftsinformatik und Neue Medien" (Information Systems and New Media) at the "WU" (Vienna University of Economics and Business) as well as the developers and consultants of "Knowledge Markets" Consulting Ges.m.b.H. in Vienna for their innumerable contributions. 


\section{Appendix: Content Analysis Using the Design Recommendation "Benchmark Values" as an Example}

\begin{tabular}{|c|c|c|c|}
\hline Company & Paraphrase & Generalization & Reduction \\
\hline A & - & - & $\begin{array}{l}\text { Benchmark Values: Some } \\
\text { companies consider benchmark }\end{array}$ \\
\hline B & - & - & values coming with the given \\
\hline $\mathrm{C}$ & - & - & $\begin{array}{l}\text { instruments, performance } \\
\text { indicators and competency }\end{array}$ \\
\hline $\mathrm{D}$ & $\begin{array}{l}\text { Comparing stored data: }(1) \text { a } \\
\text { trainer has several courses } \rightarrow \text { the } \\
\text { evaluation of the trainer in the } \\
\text { individual courses are to be } \\
\text { compared with each other, }(2) \\
\text { comparisons over time are useful } \\
\text { for program development, }(3) \\
\text { internal benchmarks are helpful } \\
\text { for assessing lecturers, }(4) \\
\text { recording performance curves }\end{array}$ & $\begin{array}{l}\text { Providing benchmarks comes } \\
\text { with many interesting areas of } \\
\text { application. It must be } \\
\text { differentiated between internal } \\
\text { and external benchmarks. } \\
\text { Internal benchmarks are } \\
\text { particularly interesting for } \\
\text { performance assessments within } \\
\text { the own trainer pool and for } \\
\text { comparisons over time. }\end{array}$ & $\begin{array}{l}\text { models as additional benefit. } \\
\text { Internal benchmarks for } \\
\text { evaluating training providers are } \\
\text { of particular interest. Using } \\
\text { external benchmark values } \\
\text { within the company, however, } \\
\text { requires transparency in } \\
\text { calculating them because the data } \\
\text { of the benchmark partners must } \\
\text { match the in-house data. }\end{array}$ \\
\hline
\end{tabular}

$\mathrm{E}$

$\mathrm{F}$

G

$\mathrm{H}$

I

$\mathrm{J}$

$\mathrm{K}$

The question template pool is particularly interesting for experts because of the possibility of a benchmark comparison.

L

M

A tool developed in-house is used for the evaluation. In contrast, the presented company-wide solution is too general, insufficiently adaptable and insufficient for the particular company culture.
Providing benchmarks is a significant benefit. Benchmarks should be easy to integrate into reports.

Managers are also interested in quality-controlled questionnaire templates. A benchmark comparison would also be interesting.

Benchmark data is collected using standardized feedback instruments for supporting the assessment of the offered lecturers.

Human resource developers consider it interesting to conduct a benchmark comparison.

Company-wide evaluation seems to fail because of the individualization required for performance assessments. 


\section{References}

Argote L, McEvily B, Reagans R (2003) Managing knowledge in organizations: an integrative framework and review of emerging themes. Management Science 49(4):571582

Atteslander P (2008) Methoden der empirischen Sozialforschung. Erich Schmidt, Berlin

Baskerville R, Wood-Harper AT (1998) Diversity in information systems action research methods. European Journal of Information Systems 7(2):90-107

Caffarella RS (2002) Planning programs for adult learners - a pratical guide for educators, trainers, and staff developers. Wiley, San Francisco

Czerny E (2009) Nachhaltiges Kompetenzmanagement: mit den Kompetenzen der Mitarbeiter zu dauerhaftem Unternehmenserfolg; eine ressourcenorientierte Betrachtung. Müller, Saarbrücken

Davis FD (1989) Perceived usefulness, perceived ease of use and user acceptance of information technology. MIS Quarterly 13(3):319-339

Davison RM, Martinsons MG, Kock G (2004) Principles of canonical action research. Information Systems Journal 14:65-86

Deiser R (2009) Designing the smart organization - how breakthrough corporate learning initiatives drive strategic change and innovation. Jossey-Bass, San Francisco

DeLone WH, McLean ER (2003) The DeLone and McLean model of information systems success: a ten-year update. Journal of Management Information Systems 19(4):9-30

Devaraj S Babu SR (2004) How to measure the relationship between training and job performance. Communications of the ACM 47(5):63-67

Easterby-Smith $M$, Thorpe $R$, Jackson PR (2008) Management research. Sage, London

EC (2001) Making a European area of lifelong learning a reality. European Commission, Brussels

Edwards MR, Ewen AJ (2000) 360 Beurteilung - Klareres Feedback, höhere Motivation und mehr Erfolg für alle Mitarbeiter. Beck, München

Engelhart W, Kleinaltenkamp M, Rechenfelderbäumer M (1993) Leistungsbündel als Absatzobjekte - Ein Ansatz zur Überwindung der Dichotomie von Sach- und Dienstleistungen. zfbf - Zeitschrift für betriebswirtschaftliche Forschung 45(5):395426

Erpenbeck J, Sauter W (2007) Kompetenzentwicklung im Netz - New Blended Learning mit Web 2.0. Luchterhand, Köln
Faltin N, Zimmermann V (2009) Nutzloses Training adé - Prozessorientierte Lerntechnologien für kompetente Mitarbeiter. Information Management \& Consulting 24(1):614

Gregor S, Jones D (2007) The anatomy of a design theory. Journal of the Association for Information Systems 8(5):312-355

Hamel G (2007) The future of management. Harvard Business School Press, Boston

Hasenkamp U, Stahlknecht P (2009) Das Fach Wirtschaftsinformatik im Spiegel seiner Zeitschrift. WIRTSCHAFTSINFORMATIK 51(1):18-27

Hertel G, Konradt U (2004) Human Resource Management im Inter- und Intranet: Inhalte und Überblick. In: Hertel G, Konradt $\mathrm{U}$ (eds) Human Resource Management im Inter- und Intranet. Hogrefe, Göttingen

Hevner AR, March ST Park J (2004) Design research in information systems research. MIS Quarterly 20(1):75-105

Heyse V, Ortmann S (2008) Talentmanagement in der Praxis: Eine Anleitung mit Arbeitsblättern, Checklisten, Softwarelösungen. Waxmann, Münster

Kirkpatrick DL, Kirkpatrick JD (2005) Evaluating training programs: the four levels. Berrett-Koehler, Berkley

Knowles MS (1986) Using learning contracts practical approaches to individualizing and structuring learning. Jossey-Bass, San Francisco

Laudon KC, Laudon JP (2005) Essentials of management information systems. Pearson Education, Upper Saddle River

Lindgren R, Henfridsson O, Schultze U (2004) Design principles for competence management systems: a synthesis of an action research study. MIS Quarterly 28(3):435-472

Macharzina K, Wolf J (2008) Unternehmensführung. Gabler, Wiesbaden

Maier R, Hädrich T (2001) Modell für die Erfolgsmessung von Wissensmanagementsystemen. WIRTSCHAFTSINFORMATIK 43(5):497-509

Markus ML, Majchrzak A, Gasser L (2002) A design theory for systems that support emergent knowledge processes. MIS Quarterly 26(3):179-212

Mayring P (2010) Qualitative Inhaltsanalyse - Grundlagen und Techniken. Beltz, Weinheim

Patton MQ (2002) Qualitative research \& evaluation methods. Sage, Thousand Oaks

Phillips JJ (2003) Return on investment in training and performance improvement programs. Butterworth \& Heinemann, Amsterdam

Picot A, Baumann O (2009) Die Bedeutung der Organisationstheorie für die Ent- wicklung der Wirtschaftsinformatik. WIRTSCHAFTSINFORMATIK 51(1):72-81

Prahalad CK, Hamel G (1990) The core competence of the corporation. Harvard Business Review 68(3):79-91

Probst G, Raub S, Romhardt K (2000) Managing knowledge. Building blocks for success. Wiley, Chichester

Rosenstiel LV (2006) Entwicklung von Werthaltungen und individueller Kompetenz. In: Sonntag K (ed) Personalentwicklung in Organisationen. Hogrefe, Göttingen

Rubin HJ, Rubin IS (1995) Qualitative Interviewing. Sage, Thousand Oaks

Schuler H, Görlich Y. (2006) Ermittlung erfolgsrelevanter Merkmale von Mitarbeitern. In: Sonntag K (ed) Personalentwicklung in Organisationen. Hogrefe, Göttingen

Seeber S (2000) Stand und Perspektiven von Bildungscontrolling. In: Seeber S, Krekel E, Van Buer J (eds) Bildungscontrolling: Ansätze und kritische Diskussion zur Effizienzsteigerung von Bildungsarbeit. Lang, Frankfurt am Main

Simon B, Ostertag R, Machal R, Weihs $\mathrm{P}$ (2008) Qualifizierung von Lieferanten über eLearning - Ein Pilotprojekt der Daimler AG. HMD - Praxis der Wirtschaftsinformatik 259:96-104

Simon B, Treiblmaier H (2007) Von der Qualitätssicherung zum Bildungscontrolling: Fortbildungsmanagement unter der $\mathrm{Ef}$ fektivitätslupe. In: Breitner $\mathrm{MH}$, Bruns $\mathrm{B}$, Lehner F (eds) Neue Trends im E-Learning: Aspekte der Betriebswirtschaftslehre und Informatik. Physica-Verlag, Heidelberg

Solga M, Ryschka J, Mattenklott A (2008) Personalentwicklung: Gegenstand, Prozessmodell, Erfolgsfaktoren. In: Ryschka J, Solga M, Mattenklott A (eds) Praxishandbuch Personalentwicklung - Instrumente, Konzepte, Beispiele. GMW, Wiesbaden

Sonntag K (2005) Personalentwicklung in Organisationen. Hogrefe, Göttingen

Steinweg S (2009) Systematisches Talent Management: Kompetenzen strategisch einsetzen. Schäffer-Poeschel, Stuttgart

Strohmeier S (2000) Informatisierung der Personalwirtschaft: Eine kritische Bestandsaufnahme gegenwärtiger Forschung. WIRTSCHAFTSINFORMATIK 42(Sonderheft): 90-96

Venkatesh V (2000) Determinants of perceived ease of use: integrating control intrinsic motivation, and emotion into the technology acceptance model. Information Systems Research 11(4):342-365

Zwick T (2004) Weiterbildungsintensität und betriebliche Produktivität. Zeitschrift für Betriebswirtschaft 74(7):651-668 